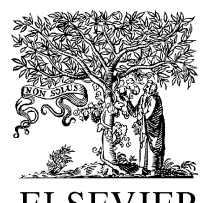

Journal of Photochemistry and Photobiology A: Chemistry 126 (1999) 51-58

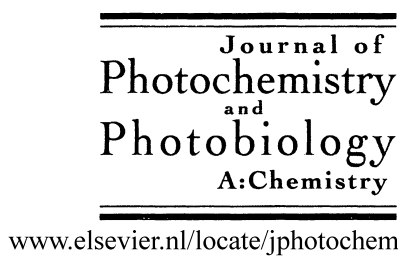

\title{
Singlet molecular oxygen photosensitized by Rhodamine dyes: correlation with photophysical properties of the sensitizers
}

\author{
F. Stracke, Ma. Heupel, E. Thiel* \\ University of Siegen, Department of Physical Chemistry II, Adolf-Reichwein-Straße 2, D-57068, Siegen, Germany
}

Received 2 February 1999; received in revised form 25 May 1999; accepted 1 June 1999

\begin{abstract}
By measuring its IR phosphorescence the formation of singlet molecular oxygen ${ }^{1} \mathrm{O}_{2}$ photosensitized by rhodamine dyes is directly proved. The ${ }^{1} \mathrm{O}_{2}$ formation rate is compared with that expected from the low probability $(\approx 1 \%)$ of intersystem crossing of the photosensitizers. The quantum yield for triplet population and the triplet lifetime of the investigated dyes is measured by using a laser-scanning-microscopy technique. The influence of quenching agents (nitrobenzene and COT) is discussed. It results that the formation of ${ }^{1} \mathrm{O}_{2}$ can be prevented effectively by quenching of the $\mathrm{S}_{1}$ or T state of the photosensitizer. The influence of the molecular ground-state oxygen ${ }^{3} \mathrm{O}_{2}$ concentration $\left[{ }^{3} \mathrm{O}_{2}\right]$ is investigated. The presence of the paramagnetic ${ }^{3} \mathrm{O}_{2}$ leads to an increased $\mathrm{S}_{1} \rightarrow \mathrm{T}$ intersystem crossing rate of the photosensitizers and therefore to a reinforced formation of singlet molecular oxygen. It is found for rhodamine $6 \mathrm{G}$ as well as for rose bengal that in air-saturated acetonitrile nearly the half of the excited dye triplets are quenched by molecular oxygen. The ${ }^{1} \mathrm{O}_{2}$ concentration can be significantly reduced by decreasing the ${ }^{3} \mathrm{O}_{2}$ concentration below its air saturated level. (C)1999 Elsevier Science S.A. All rights reserved.
\end{abstract}

Keywords: Singlet molecular oxygen; Exited state quenching; Rhodamine; Intersystem crossing; Phosphorescence

\section{Introduction}

Xanthene derivatives especially rhodamine dyes, occupy an important position among different families of dyes, owing to a number of reasons related to their photochemical and photophysical properties. Because of their high fluorescence quantum yield rhodamine dyes have wide spread technological and scientific applications e.g. single molecule detection [1,2], fluorescence labelling [3], dye lasers [4-6], conversion and storage of solar energy [7] etc. These dyes are also applied in medicine e.g. for the staining of damaged cells [8], as antitumor agent [9], and in photosensitized cell killing [10]. For nearly all applications a high photostability is required. This goal can be approached by increasing the deactivation of the excited molecules to their ground states. Consequently the competition of photochemical processes will be suppressed and therefore their importance decreases. Owing to its metastable character for photochemical reaction the triplet state $\mathrm{T}$ is of particularly interest.

\footnotetext{
* Corresponding author. Tel.: +49-271-740-4478; fax: +49-271-740-2883

E-mail address: e.thiel@mail.pc.chemie.uni-siegen.de (E. Thiel)
}

In dye laser technology a short triplet state lifetime is of two fold importance. Besides an increased photostability a reduced triplet state lifetime leads to a decreased triplet-triplet absorption which can be decisive for laser efficiency [11-16]. Molecular parameters important for dye laser action for a number of rhodamine dyes were measured in our group by using a time resolved laser-scanning-microscopy technique $[17,18]$.

Because of the low lying excited singlet state of the omnipresent molecular oxygen this molecule frequently operates as efficient intermolecular quencher for excited singlet and triplet states. As reaction product the chemically highly reactive ${ }^{1} \mathrm{O}_{2}$ can be formed [19-24]. This molecular species may activate the photodecomposition of the dye molecules or can lead to a phototoxical action of the dye.

Several techniques have been used to detect ${ }^{1} \mathrm{O}_{2}$ in condensed phase like ${ }^{1} \mathrm{O}_{2} \rightarrow{ }^{3} \mathrm{O}_{2}$ NIR phosphorescence [25-33], time resolved thermal lens spectroscopy [26,34,35], and the analysis of ${ }^{1} \mathrm{O}_{2}$ specific reaction products $[21,29,36-41]$. Quantum yields of ${ }^{1} \mathrm{O}_{2}$ production have been investigated for a large number of sensitizers. Even for a couple of hydroxy xanthenes which show a relatively high triplet quantum yield as fluoresceine, eosin and rose bengal values for 
Table 1

Structures of the investigated dyes

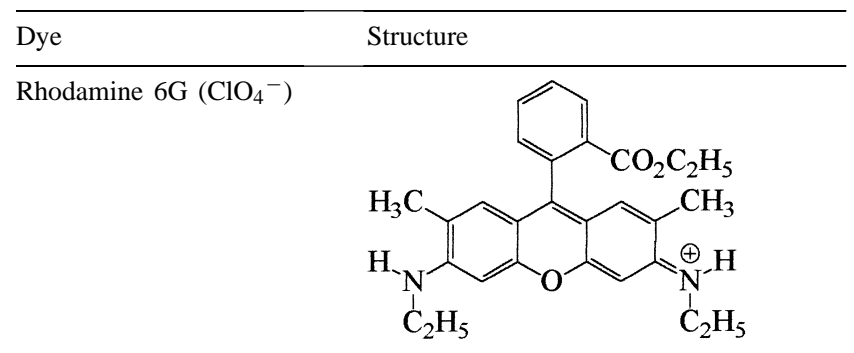

Rose bengal $\left(\mathrm{Na}^{+}\right)_{2}$<smiles>O=C([O-])c1c(Cl)c(Cl)c(Cl)c(Cl)c1-c1c2cc(I)c(=O)c(I)c-2oc2c(I)c([O-])c(I)cc12</smiles>

Rhodamine $630\left(\mathrm{ClO}_{4}^{-}\right)$

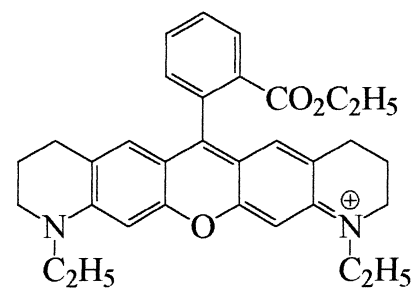

Methylene blue $\left(\mathrm{Cl}^{-}\right)$

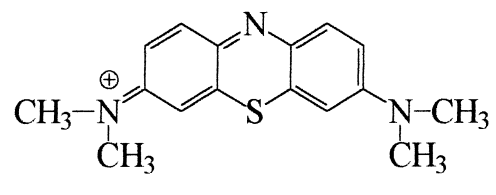

${ }^{1} \mathrm{O}_{2}$ production rates are reported [35,36,42]. Rhodamine dyes possess a very low triplet quantum yield ( $1 \%$ or less) [43]. Only few experiments $[40,41,44-46]$ have been performed in order to prove the formation of ${ }^{1} \mathrm{O}_{2}$ sensitized by rhodamine dyes. This is perhaps surprising in view of the frequently discussed relation between the photostability of xanthene dyes and the presence of ${ }^{1} \mathrm{O}_{2}[35,42$, 47-53].

In the present paper, the formation of ${ }^{1} \mathrm{O}_{2}$ photosensitized by rhodamine dyes is directly proved. The detection of the ${ }^{1} \mathrm{O}_{2}$ is provided by the sensitive detection of its phosphorescence near $1.27 \mu \mathrm{m}$. A kinetic theory is presented and verified by the experiment. It is shown that the formation of the ${ }^{1} \mathrm{O}_{2}$ can be prevented. For that purpose the influence of quenching agents for the rhodamine dyes in their first excited singlet $S_{1}$ and triplet $T$ states is investigated.

The results are compared to the predictions, which are expected from the measurement of the molecular dynamics (rate constant $k_{\mathrm{ST}}$ for $\mathrm{S}_{1} \rightarrow \mathrm{T}$ intersystem crossing and triplet lifetime $\tau_{\mathrm{T}}$ ) of the investigated dyes. The measurement of these parameters is carried out by using a laser-scanning-microscopy technique $[17,18,43,54]$.

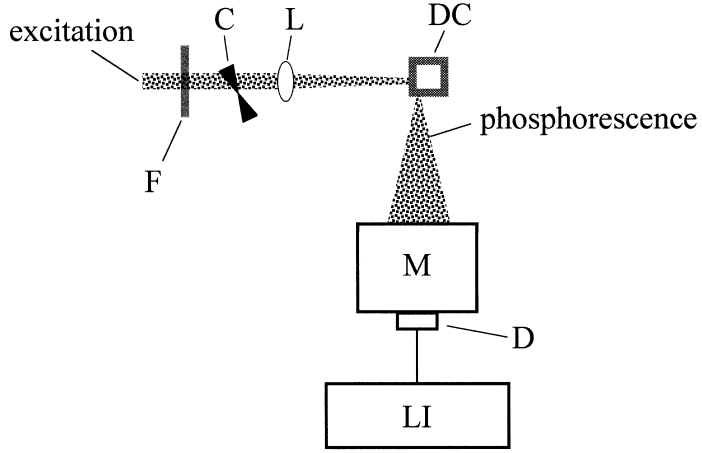

Fig. 1. Phosphorescence spectrometer. Excitation: Kr-ion laser (model CR $3000 \mathrm{~K}$, Coherent Radiation) or Ar-ion laser (model Innova 70, Coherent Radiation); C: Chopper (model 220A, HMS, driven at $170 \mathrm{~Hz}$ ); L: Lens (150 mm focal length); DC: Dye cell $(1 \mathrm{~cm} \times 1 \mathrm{~cm}$, fused silica); F: Optical bandpass filter (model KG $5(1 \mathrm{~mm})$ in combination with BG 39 $(3 \mathrm{~mm})$ for excitation at $514.5 \mathrm{~nm}$ and $\mathrm{KG1}(3 \mathrm{~mm})$ in combination with OG $590(3 \mathrm{~mm})$ for excitation at $647.1 \mathrm{~nm}$, Schott); M: Monochromator setup (shown in Fig. 2); D: Detector (InGaAs diode, model G5832-01, Hamamatsu, driven at room temperature); LI: Lock-in amplifier (model SR 850 DSP, Stanford Research Systems).

\section{Experimental details}

The investigated dyes (photosensitizers) were solved in acetonitrile (spectroscopic grade, Merck). Their chemical structures are shown in Table 1. The investigated dyes were checked for purity by thin layer chromatography. Rhodamine 6G (laser grade, Exciton), rose bengal (632-69-9, Acros) and methylene blue (CI 52015, Merck) were used without further purification. Rhodamine 630 was synthesized and purified in the lab of Prof. K. H. Drexhage, University of Siegen, Germany. The rhodamine dyes were also checked for purity by high-performance liquid chromatography and did not contain a significant amount of impurities. As quenching agent 1,3,5,7-cyclooctatetraene (COT) (Radiant dyes) and nitrobenzene (puriss. p.a., Fluka) was applied. The ${ }^{3} \mathrm{O}_{2}$ concentration is adjusted by bubbling $(15 \mathrm{~min})$ with the corresponding $\mathrm{N}_{2}-\mathrm{O}_{2}$-gas mixture. The solubility of ${ }^{3} \mathrm{O}_{2}$ in acetonitrile is $k_{\text {Henry }}=9.1 \times 10^{-3} \mathrm{~mol} /(1 \mathrm{~atm})$ [55]. Assuming an ideal behaviour of gaseous elements in acetonitrile and almost complete gas displacement, one yields for the ${ }^{3} \mathrm{O}_{2}$ concentration $\left[{ }^{3} \mathrm{O}_{2}\right]$ the values $9,1.8$ and $<0.1 \mathrm{mM}$ for ${ }^{3} \mathrm{O}_{2}$, air and nitrogen flushed solution.

The dye solution is placed in a fluorescence cell DC of $1 \mathrm{~cm} \times 1 \mathrm{~cm}$ thickness (see Fig. 1) and irradiated by a collimated laser beam. The focal plane of the lens $\mathrm{L}$ is $40 \mathrm{~mm}$ behind the dye cell. The mode diameter $\theta_{\mathrm{m}}$ of the laser beam at the entrance of the dye cell is $\approx 500 \mu \mathrm{m}$. In order to suppress infrared radiation which is emitted from the excitation laser discharge the cut off filter $\mathrm{F}$ is used. The laser light excites dye molecules from their ground state to the first excited singlet state, which either return rapidly to their ground state or intersystem cross to a lower lying triplet state. By quenching of the photosensitizers triplet state with ${ }^{3} \mathrm{O}_{2},{ }^{1} \mathrm{O}_{2}$ can be formed. The ${ }^{1} \mathrm{O}_{2}$ phosphorescence is detected per- 


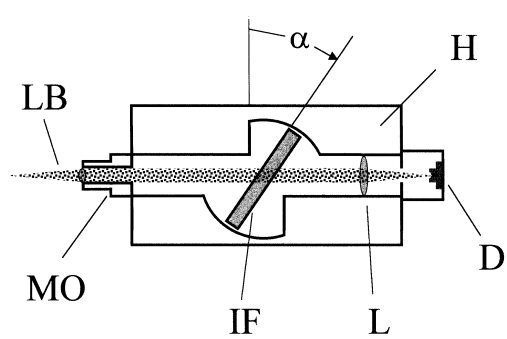

Fig. 2. Highly sensitive monochromator. LB: Light beam; MO: Microscope objective (model $10 \times, 0.25,160,15 \mathrm{~mm}$ focal length, Spindler and Hoyer), L: Lens (50 mm focal length); D: Detector (1 mm diameter, model G5832-01, Hamamatsu, driven at room temperature); this arrangement provides a visual field of $\theta_{\mathrm{vf}} \approx 300 \mu \mathrm{m}$ diameter; IF: Tiltable mounted interference filter (model NBP-1300-25-2, Infrared Engineering ); $\alpha$ : Angle of tilting from normal incidence; H: Housing and light-tight mounting.

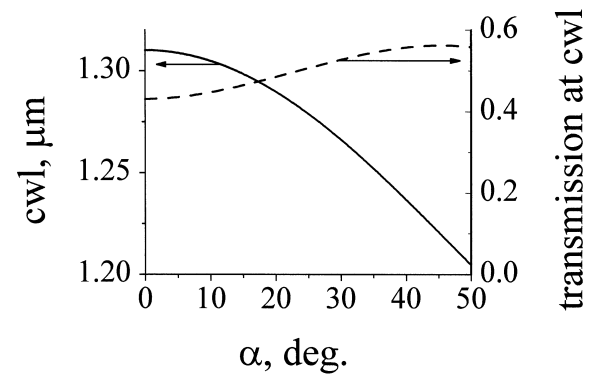

Fig. 3. Central wavelength (cwl) and maximal transmission of the interference filter described in Fig. 2. The spectral resolution is approximately $1.8 \times 10^{-2}(25 \mathrm{~nm} \mathrm{fwhm})$ and nearly independent of the wavelength. The measured is carried out by a spectrophotometer (model Lambda 19, Perkin Elmer).

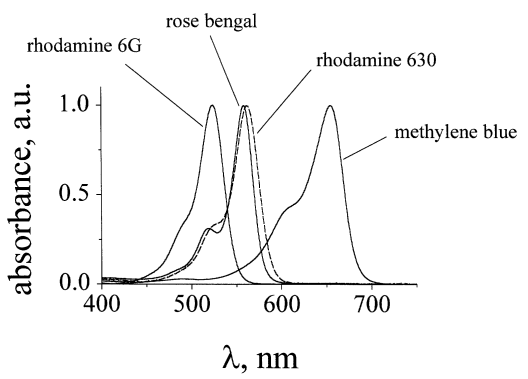

Fig. 4. Absorption spectra of the applied dyes (photosensitizers) in acetonitrile (normalised). At the absorption maxima a molar decadic extinction coefficient of $10^{5} \mathrm{l} /(\mathrm{mol} \mathrm{cm})$ is assumed.

pendicular to the laser beam. As spectrometer a specially designed highly sensitive monochromator is used (see Fig. 2). It consists of a microscope objective MO, which collects a large fraction of the emitted phosphorescence photons. The subsequent wavelength selection is carried out by a narrow band interference filter IF. By tilting this filter away from perpendicular incidence its transmission wavelength is shifted to a shorter wavelength as shown in Fig. 3. This apparatus allows to sensitively record luminance spectra from 1210 to $1310 \mathrm{~nm}$. The spectral resolved light is focused on a InGaAs photodiode ( $1 \mathrm{~mm}$ diameter) used at room temperature. The magnification given by the detection optics is 3.3 fold (see Fig. 2). Thus the length $\theta_{\mathrm{vf}}$ of the sensing volume is $300 \mu \mathrm{m}$. For the sensing volume $V$ results $V=\theta_{\text {vf }} \theta_{\mathrm{m}}^{2} \pi / 4 \approx 0.06 \mathrm{~mm}^{3}$.

In order to increase the signal to noise ratio the excitation beam is chopped and the detector current is recorded by a lock-in amplifier. All measurements are carried out at room temperature and under identical conditions (with respect to excitation power and wavelength, sample absorption and setup adjustment).

The ground state absorption (see Fig. 4) and fluorescence spectra are measured by a spectrophotometer (model Lambda 19, Perkin Elmer) and a fluorimeter (model Fluorolog, Spex). The fluorescence lifetime of the dyes is measured by single photon counting and carried out by S. Nord, University of Heidelberg, Germany.

For the determination of the excited-state kinetics of the dyes $\left(S_{1} \rightarrow T\right.$ intersystem crossing rate constant and triplet lifetime) a laser-scanning microscope is applied. Experimental details are described elsewhere $[43,56]$. Briefly, the sample consists of a dye solved in acetonitrile. The dye solution is moved by using a fast spinning dye cell $(l=200 \mu \mathrm{m}$ thickness). A continuous excitation beam (Ar-ion laser, absorbed power $\approx 100 \mathrm{~mW}$ ) is focused onto the sample. Owing to the motion of the dye cell long living transients will be transported downstream. This provides a characteristic spatial distribution of transient states. The transmission of the sample is measured using a continuous probe beam (Ar-or $\mathrm{Kr}$-ion laser) which is focused downstream of the excitation focus. Due to the adjustable distance between the foci of the probe and the excitation beam the complete distribution of transient states in the sample is detectable. Because of the motion of the sample the spatial evolution of the transmission can be transformed into the time domain. Consequently, it is possible to identify individual states by analysing the temporal decrease of the transient absorption. The waist diameter $a$ of the focused beams is $15 \mu \mathrm{m}$. A typical sample velocity $v_{\text {jet }}$ is $70 \mathrm{~m} \mathrm{~s}^{-1}$ which can be converted to a time resolution of $a / v_{\text {jet }}=200 \mathrm{~ns}$. In order to increase the signal to noise ratio the excitation beam is chopped and the detector current is recorded by a lock-in amplifier. With this technique transient absorptions down to $10^{-7}$ can be detected.

\section{Theory}

The analysis of the recorded signal is carried out on the basis of a reaction scheme system shown in Fig. 5. This scheme is usually accepted for the ${ }^{1} \mathrm{O}_{2}$ production [19,20,34,39]. After excitation of the photosensitizer to its first excited singlet $S_{1}$ (Fig. 5(a)) state via intersystem crossing the lowest triplet state $\mathrm{T}$ is populated (Fig. 5(e)). The $\mathrm{T}$ state is deactivated by intermolecular interaction either with ${ }^{3} \mathrm{O}_{2}$ (Fig. $5(i, j)$ ) (predominant energy transfer, under certain conditions electron transfer [57]), with an added triplet quencher Q (Fig. 5(h)) or with other triplet quenchers (Fig. 5(g)) (e.g. impurities which are present in the solution in a low 


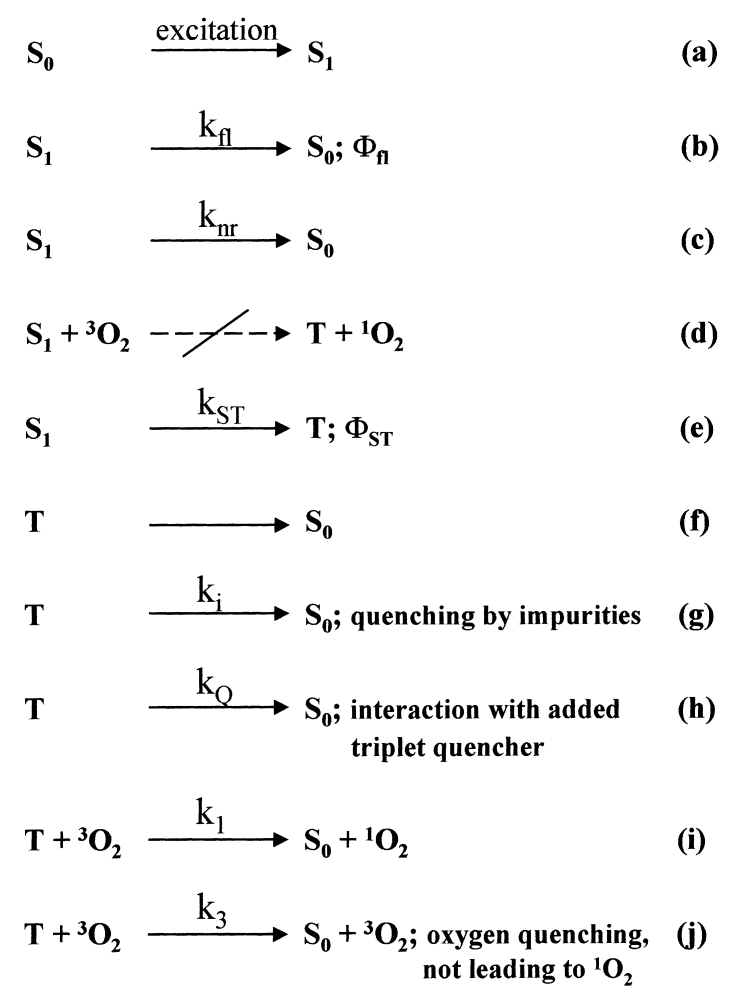

Fig. 5. Reaction scheme system. $\mathrm{S}_{0}, \mathrm{~S}_{1}, \mathrm{~T}$ : Photosensitizers ground, first excited singlet and triplet state. $\Phi_{\mathrm{fl}}$ and $\Phi_{\mathrm{ST}}$ : Quantum yield for fluorescence and intersystem crossing. The definition of the rate constants is given in context with Eq. (1)-(3).

concentration). As shown in Fig. 5(i) the triplet quenching can lead to the formation of ${ }^{1} \mathrm{O}_{2}$. The formation of ${ }^{1} \mathrm{O}_{2}$ by deactivation of the $S_{1}$ state (Fig. 5(d)) is also spin allowed but energy forbidden. The energy gap between the $S_{1}$ and the $\mathrm{T}$ state of the investigated rhodamines is only $3100 \mathrm{~cm}^{-1}$ [58] and therefore not sufficient to excite the ${ }^{1} \mathrm{O}_{2}$ to its energy level $\left(7882 \mathrm{~cm}^{-1}[29]\right)$.

The measurable oxygen phosphorescence is proportional to the ${ }^{1} \mathrm{O}_{2}$ concentration. In order to calculate the ${ }^{1} \mathrm{O}_{2}$ concentration it is useful to consider the following rate equations of the photosensitizers $\mathrm{S}_{1}$ and $\mathrm{T}$ state and for the ${ }^{1} \mathrm{O}_{2}$.

$\frac{\mathrm{d}\left[\mathrm{S}_{1}\right]}{\mathrm{d} t}=P_{\mathrm{A}}-\frac{\left[\mathrm{S}_{1}\right]}{\tau_{\mathrm{S}}}$

$\frac{\mathrm{d}[\mathrm{T}]}{\mathrm{d} t}=k_{\mathrm{ST}}\left[\mathrm{S}_{1}\right]-[\mathrm{T}]\left(\left(k_{1}+k_{3}\right)\left[{ }^{3} \mathrm{O}_{2}\right]+k_{\mathrm{Q}}[\mathrm{Q}]+k_{\mathrm{i}}\right)(2)$

$\frac{\mathrm{d}\left[{ }^{1} \mathrm{O}_{2}\right]}{\mathrm{d} t}=k_{1}\left[{ }^{3} \mathrm{O}_{2}\right][\mathrm{T}]-\frac{\left[{ }^{1} \mathrm{O}_{2}\right]}{\tau_{\Delta}}$

with [T] concentration of the $\mathrm{T}$ state, $\left[\mathrm{S}_{1}\right], \tau_{\mathrm{S}}$ concentration and lifetime of the $\mathrm{S}_{1}$ state, $\left[{ }^{1} \mathrm{O}_{2}\right], \tau_{\Delta}$ concentration and lifetime of ${ }^{1} \mathrm{O}_{2},\left[{ }^{3} \mathrm{O}_{2}\right]$ concentration of ${ }^{3} \mathrm{O}_{2}$, [Q] concentration of an additive $\mathrm{Q}$ which quenches the $\mathrm{T}$ state, $k_{1}$ and $k_{3}$ rate constant for the quenching of the T state by ${ }^{3} \mathrm{O}_{2}$ according Fig. 5(i, j), $k_{\mathrm{Q}}$ rate constant for the quenching of the $\mathrm{T}$ state by the additive $\mathrm{Q}, k_{\mathrm{i}}$ deactivation rate constant of the $\mathrm{T}$ state in absence of ${ }^{3} \mathrm{O}_{2}$ and any additive $\mathrm{Q}$.
The definition of the above-mentioned values are given as an average over the sensing volume. $P_{\mathrm{A}}$ is the population rate of the $S_{1}$ state caused by laser excitation and given by

$$
P_{\mathrm{A}}=\frac{P \lambda}{h c N_{\mathrm{A}} V}
$$

Here $V$ is the sensing volume. $P$ the absorbed laser power at the wavelength $\lambda$. The $h, c$ and $N_{\mathrm{A}}$ are Planck's constant, vacuum velocity of light and Avogadro's constant, respectively.

If the duration of the excitation (half chopper period) is much longer than the relaxation time of the system to its equilibrium all derivations (Eqs. (1)-(3)) will be zero which leads to

$\left[{ }^{1} \mathrm{O}_{2}\right]=\frac{P_{\mathrm{A}} \tau_{\Delta}}{1+k_{3} / k_{1}} \times \Phi_{\mathrm{ST}} \times \Phi_{\mathrm{O}_{2}}$

with the quantum yield $\Phi_{\mathrm{ST}}$ for intersystem crossing

$\Phi_{\mathrm{ST}}=k_{\mathrm{ST}} \tau_{\mathrm{S}}$

and $\Phi_{\mathrm{O}_{2}}$ the yield for triplet quenching by ${ }^{3} \mathrm{O}_{2}$ which is given by

$$
\Phi_{\mathrm{O}_{2}}=\frac{1}{1+\left(k_{\mathrm{Q}}[\mathrm{Q}]+k_{\mathrm{i}}\right) /\left(\left(k_{1}+k_{3}\right)\left[{ }^{3} \mathrm{O}_{2}\right]\right)}
$$

The lifetime $\tau_{\mathrm{T}}$ of the T state can be written as [59]

$$
\frac{1}{\tau_{\mathrm{T}}}=\frac{1}{\tau_{\mathrm{T}}^{0}}+\left(k_{1}+k_{3}\right)\left[{ }^{3} \mathrm{O}_{2}\right]
$$

where $\tau_{\mathrm{T}}^{0}=1 /\left(k_{\mathrm{Q}}[\mathrm{Q}]+k_{\mathrm{i}}\right)$ represents the triplet lifetime in absence of molecular oxygen. Because of its paramagnetism the presence of ${ }^{3} \mathrm{O}_{2}$ leads to an increased probability of intersystem crossing given by [60].

$k_{\mathrm{ST}}=k_{\mathrm{ST}}^{0}+m_{\mathrm{S}}\left[{ }^{3} \mathrm{O}_{2}\right]$

where the value of $k_{\mathrm{ST}}^{0}$ and $m_{\mathrm{S}}$ does not depend on the ${ }^{3} \mathrm{O}_{2}$ concentration. $m_{\mathrm{S}}$ is a constant which describes the enhancement of intersystem crossing by the presence of oxygen. The variation in the value of $k_{\mathrm{ST}}$ also influences the lifetime of the $S_{1}$ state given by

$\tau_{\mathrm{S}}=\frac{1}{k_{\mathrm{fl}}+k_{\mathrm{nr}}+k_{\mathrm{ST}}}$

where $k_{\mathrm{fl}}$ and $k_{\mathrm{nr}}$ are the rate constants for fluorescence and with exception of intersystem crossing the nonradiative deactivation rate constant of the $S_{1}$ state of the photosensitizer. For the triplet quantum yield follows with Eqs. (6), (9) and (10)

$$
\Phi_{\mathrm{ST}}=\frac{1}{1+\left(k_{\mathrm{fl}}+k_{\mathrm{nr}}\right) /\left(k_{\mathrm{ST}}^{0}+m_{\mathrm{S}}\left[{ }^{3} \mathrm{O}_{2}\right]\right)}
$$

The oxygen dependency of $k_{\mathrm{fl}}$ and $k_{\mathrm{nr}}$ is neglected. With Eqs. (5) and (11) the concentration of ${ }^{1} \mathrm{O}_{2}$ can be calculated 

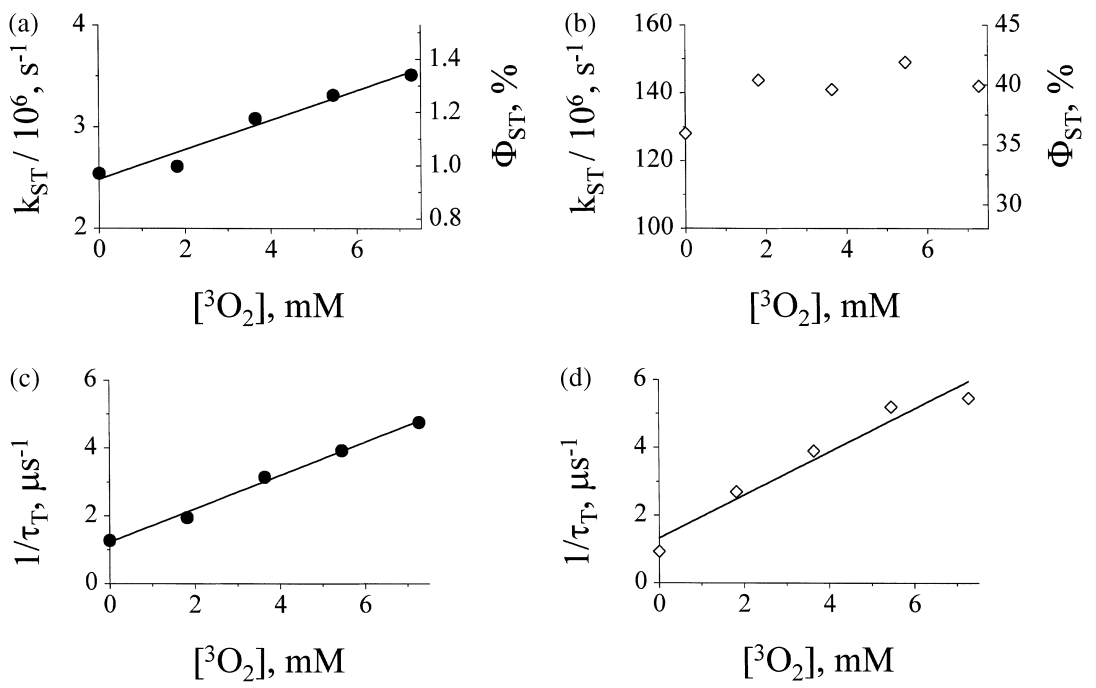

Fig. 6. Excited state properties of rhodamine $6 \mathrm{G}$ and rose bengal in acetonitrile as function of the ${ }^{3} \mathrm{O}_{2}$ concentration. The dye concentration is approximately $0.2 \mathrm{mM}$. The dark circle $(\bullet)$ and rectangle $(\diamond)$ are measured values for rhodamine $6 \mathrm{G}$ and rose bengal (the measurement technique is described in [17,54]), The solid line (-) is linear fit (compare Eq. (8) and (9)). The fit parameter are given in Table 2.

from its lifetime, the ${ }^{3} \mathrm{O}_{2}$ concentration and the molecular properties of the photosensitizer.

Rhodamine dyes are distinguished by their high quantum yield of fluorescence (>90\%) and a low probability for intersystem crossing (1\% or less). Therefore, one can write $\left(k_{\mathrm{fl}}+k_{\mathrm{nr}}\right) \gg k_{\mathrm{ST}}$. Consequently Eq. (11) can be simplified to

$\Phi_{\mathrm{ST}}=\frac{k_{\mathrm{ST}}^{0}+m_{\mathrm{S}}\left[{ }^{3} \mathrm{O}_{2}\right]}{k_{\mathrm{fl}}+k_{\mathrm{nr}}}$

which means that the triplet yield depends linear on the ${ }^{3} \mathrm{O}_{2}$ concentration, whereas in this approximation the lifetime of the $\mathrm{S}_{1}$ state does not depend on the ${ }^{3} \mathrm{O}_{2}$ concentration.

The population of the $\mathrm{T}$ state competes with the fluorescence (Fig. 5(b)). Thus the fluorescence quantum yield $\Phi_{\mathrm{fl}}$ is related to the quantum yield for intersystem crossing and given by

$\Phi_{\mathrm{fl}}=\frac{k_{\mathrm{fl}}}{k_{\mathrm{ST}}} \Phi_{\mathrm{ST}}$

\section{Results and discussion}

In Fig. 6, the triplet state lifetime and the rate constant for intersystem crossing of rhodamine $6 \mathrm{G}$ and rose bengal is given. In the present paper rose bengal as an established ${ }^{1} \mathrm{O}_{2}$ generator $[61,62]$ is applied as reference dye. We measure a striking low triplet quantum yield of about $40 \%$ in acetonitrile, which is consistent to the relatively high fluorescence quantum yield (36\%) of rose bengal in this solvent. These results are in good agreement with the strong dependence of rose bengals intersystem crossing rate constant on the solvent polarity [63].

Rose bengals intersystem crossing rate dependency on the ${ }^{3} \mathrm{O}_{2}$ concentration, if there is any, is smaller than the accu- racy of the measurement. The triplet quantum yield of the rhodamine dyes is in the order of $1 \%$ and clearly depends on the ${ }^{3} \mathrm{O}_{2}$ concentration. The linear dependency expected from Eq. (9) is verified. The slope of the obtained linear fits are given in Table 2 .The obtained values are in accordance with published data given for other solvents (ethanol, ethylene glycol) [56]. For the investigated sensitizers the fluorescence quantum yield and therefore the lifetime $\tau_{\mathrm{S}}$, is measured and emerges as nearly independent of the ${ }^{3} \mathrm{O}_{2}$ concentration. Thus, the quantum yield for the triplet state population is proportional to the rate constant for intersystem crossing (see Eq. (6)). Therefore, the scaling of both ordinate axis in Fig. $6(\mathrm{a}, \mathrm{b})$ is proportional.

The measured ${ }^{3} \mathrm{O}_{2}$ dependency of the sensitizers triplet lifetime (see Fig. 6(c, d)) is as expected from Eq. (8). The values obtained by the linear fit are given in Table 2 . The values of the quenching constant $\left(k_{1}+k_{3}\right)$ are in the order of magnitude expected for diffusion controlled quenching processes. In Table 3 the yield $\Phi_{\mathrm{O}_{2}}$ for triplet quenching by ${ }^{3} \mathrm{O}_{2}$ is given for air saturated solutions. For rhodamine $6 \mathrm{G}$ as well as for rose bengal nearly the half of the excited dye triplets are quenched by molecular oxygen.

As shown in Fig. 7(a) we are able to detect oxygen phosphorescence photosensitized by rhodamine 6G. By irradiation of the (dye-free) solvent no oxygen phosphorescence has been detected. This proves the signal does not origin from a solvent impurity. The rhodamine dyes where checked for purity by high-performance liquid chromatography and did not contain a significant amount of impurities which can cause the obtained oxygen phospherescence. This holds true even if the triplet quantum yield of the impurities is close to the unity. Therefore, the singlet oxygen production sensitized by impurities containing the dye sample has also been excluded. Consequently, it has been proved unambiguously that the oxygen emission is indeed sensitized by the 
Table 2

Molecular parameters of the excited sensitizers and their ${ }^{3} \mathrm{O}_{2}$ dependency. The values are measured with a laser-scanning microscope [56]

\begin{tabular}{lllccccccc}
\hline Photosensitizer & $\tau_{\mathrm{S}}^{\mathrm{a}, \mathrm{b}} / \mathrm{ns}$ & $\left(k_{\mathrm{fl}}+k_{\mathrm{nr}}\right)^{-1, \mathrm{a}, \mathrm{b}, \mathrm{c}} / \mathrm{ns}$ & $k_{\mathrm{ST}}{ }^{\mathrm{a}} / 10^{6} \mathrm{~s}^{-1}$ & $k_{\mathrm{ST}}^{0} / 10^{6} \mathrm{~s}^{-1}$ & $\Phi_{\mathrm{ST}}^{\mathrm{a}, \mathrm{d}} / \%$ & $\mathrm{~m}_{\mathrm{S}} / 10^{8} 1 /(\mathrm{mol} \mathrm{s})$ & $\tau_{\mathrm{T}}^{\mathrm{a}} / \mu \mathrm{s}$ & $\tau_{\mathrm{T}}^{0} / \mu \mathrm{s}$ & $k_{1}+k_{3} / 10^{8} 1 /(\mathrm{mol} \mathrm{s})$ \\
\hline Rhodamine 6G & 3.82 & 3.86 & 2.7 & 2.5 & 1.0 & 1.5 & 0.5 & 0.79 & 5 \\
Rhodamine 630 & 4.25 & 4.27 & 1.3 & - & 0.5 & - & 0.5 & - & - \\
Rose bengal & 2.79 & 4.53 & 140 & 140 & 40 & $<20$ & 0.4 & 0.75 & 6 \\
\hline
\end{tabular}

${ }^{\mathrm{a}}$ In air saturated acetonitrile.

${ }^{\mathrm{b}}$ The values are nearly independent of the oxygen concentration.

${ }^{\mathrm{c}}$ Calculated by Eq. (10).

${ }^{\mathrm{d}}$ Calculated by Eq. (6).

Table 3

Properties of the excited photosensitizers and ${ }^{1} \mathrm{O}_{2}$ concentrations in air saturated acetonitrile ${ }^{\mathrm{a}}$

\begin{tabular}{|c|c|c|c|c|c|c|c|}
\hline Photosensitizer & $k_{\mathrm{ST}} /\left(10^{6} \mathrm{~s}^{-1}\right)$ & $\tau_{\mathrm{S}}^{\mathrm{b}} / \mathrm{ns}$ & $\Phi_{\mathrm{ST}}^{\mathrm{c}} / \%$ & $\Phi_{\mathrm{ST}} / \Phi_{\mathrm{ST}}(\mathrm{rh} 6 \mathrm{G})^{\mathrm{d}}$ & $I_{\Delta} / I_{\Delta}(\mathrm{rh} 6 \mathrm{G})^{\mathrm{d}}$ & $\Phi_{\mathrm{O}_{2}}{ }^{\mathrm{e}} / \%$ & {$\left[{ }^{1} \mathrm{O}_{2}\right]^{\mathrm{f}} / \mu \mathrm{M}$} \\
\hline Rhodamine $6 \mathrm{G}$ & 2.7 & 3.82 & 1.0 & 1.0 & 1.0 & 42 & 1.2 \\
\hline Rhodamine 630 & 1.3 & 4.25 & 0.5 & 0.5 & 0.47 & - & - \\
\hline Rose bengal & 140 & 2.79 & 40 & 40 & 11 & 45 & 50 \\
\hline
\end{tabular}

${ }^{\text {a }}$ For the complete set of experimental data see the context to Fig. 7.

${ }^{\mathrm{b}}$ Measured by S. Nord, University of Heidelberg.

${ }^{\mathrm{c}}$ Calculated with the definition of the triplet quantum yield $\Phi_{\mathrm{T}}=k_{\mathrm{ST}} \tau_{1}$.

${ }^{\mathrm{d}}$ Normalised to the value measured with rhodamine $6 \mathrm{G}$.

${ }^{\mathrm{e}}$ Calculated by Eq. (7) and the values given in Table 2.

${ }^{\mathrm{f}}$ Calculated by Eq. (4) and (5) with $\tau_{\Delta}=60 \mu$ s $[20,67]$ and the value given in Table 2.
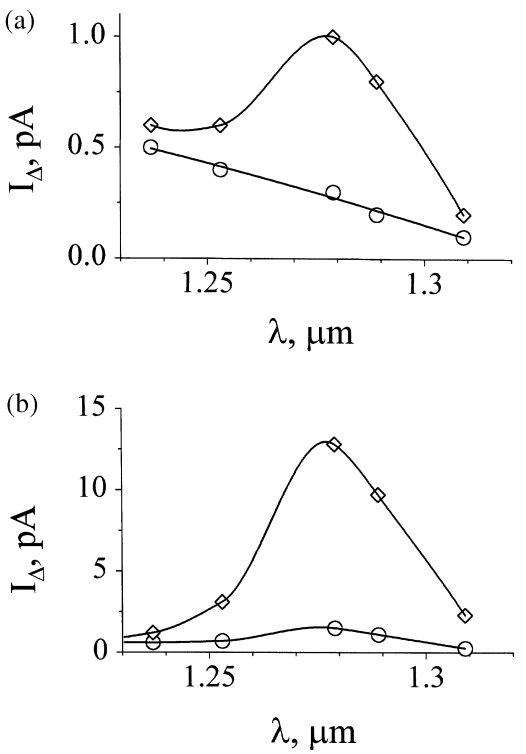

Fig. 7. Oxygen phosphorescence spectra. $I_{\Delta}$ gives the measured photocurrent. Excitation power $400 \mathrm{~mW}$, excitation wavelength $514.5 \mathrm{~nm}$ (at this wavelength for both dyes results an absorbance of $0.125 / \mathrm{mm}$ ). The rectangle $(\diamond)$ and circle $(\bigcirc)$ are measured values without addition and after addition of the triplet quencher COT $(0.3 \mathrm{M})$, the solid line (一) is probable distribution. (a) Photosensitized by rhodamine $6 \mathrm{G}$ in air saturated acetonitrile $(17 \mu \mathrm{M})$. (b) Photosensitized by rose bengal in air saturated acetonitrile $(44 \mu \mathrm{M})$.

rhodamine. Thus, for the first time with Fig. 7 we have shown that it is possible to measure the phosphorescence of ${ }^{1} \mathrm{O}_{2}$ photosensitized by a rhodamine dye.

The oxygen phosphorescence is overlapped by an emission signal, which decreases with an increasing of the detec-

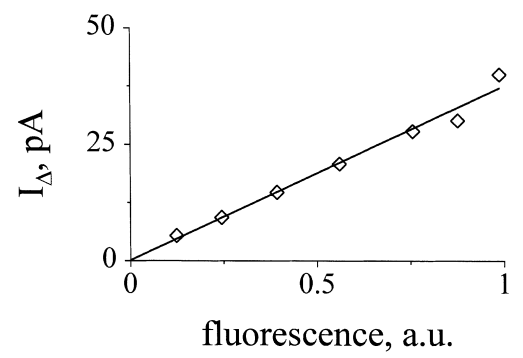

Fig. 8. Oxygen phosphorescence intensity at $1.27 \mu \mathrm{m}$ as function of the fluorescence quantum yield of the photosensitizer (rose bengal) in air saturated acetonitrile. The reduction of the fluorescence quantum yield of rose bengal is provided by addition of nitrobenzene. The rectangle $(\diamond)$ is measured values, the solid line (-) is linear fit (see Eq. (7) and (13)). The applied nitrobenzene concentrations are (from left to right) 391, 195, 98, 49, 24, 9.8 and $0.0 \mathrm{mM}$. Excitation power $450 \mathrm{~mW}$, excitation wavelength $514.5 \mathrm{~nm}$ (at this wavelength results an absorbance of $0.45 / \mathrm{mm}$ ).

tion wavelength. This signal is probably caused by the long wavelength tail of the rhodamine fluorescence.

As shown in Fig. 7 the addition of COT to the rhodamine and rose bengal solution leads to a significant reduction of the phosphorescence signal. This reduction is due to the interaction of COT with the T state of the dyes. As is shown in [59] by the presence of COT the triplet state of rhodamine dyes is effectively quenched, whereas the $S_{1}$ state and therefore the triplet quantum yield is not affected and ${ }^{1} \mathrm{O}_{2}$ only slightly interacts with COT [64]. Therefore, triplet quenching by COT competes with that by ${ }^{3} \mathrm{O}_{2}$ and should lead to the measured decrease of the ${ }^{1} \mathrm{O}_{2}$ concentration. The process is described by Eq. (5).

As can be seen from Fig. 8 the addition of nitrobenzene also reduces the ${ }^{1} \mathrm{O}_{2}$ concentration. It is known that nitroben- 


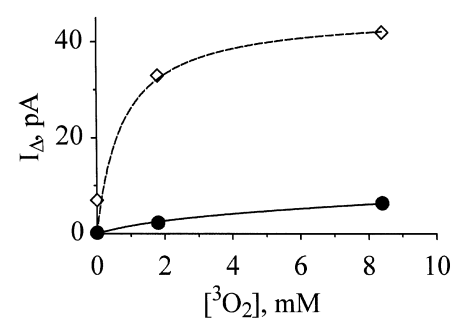

Fig. 9. Oxygen phosphorescence intensity at $1.27 \mu \mathrm{m}$ photosensitized by rhodamine $6 \mathrm{G}$ and rose bengal in acetonitrile as function of the ${ }^{3} \mathrm{O}_{2}$ concentration $\left[{ }^{3} \mathrm{O}_{2}\right]$. The rectangle $(\diamond)$ and dark circle $(\bullet)$ are measured values for rose bengal and rhodamine $6 \mathrm{G}$. The solid line $(-)$ is fitted by the distribution given by Eq. (5) with $[\mathrm{Q}]=0$ and the parameters given in Table 2.The dotted line (- - - -) is fitted by using Eq. (5) with a oxygen independent intersystem crossing rate. Excitation power $450 \mathrm{~mW}$, excitation wavelength $514.5 \mathrm{~nm}$ (at this wavelength for both dyes results an absorbance of $0.45 / \mathrm{mm})$.

zene quenches excited singlet states of various dyes by increasing the radiationless deactivation rate constant $k_{\mathrm{nr}}$. In [59] for rhodamine dyes we could show that the intersystem crossing rate constant and the triplet lifetime is not influenced by the presence of nitrobenzene. The increase of $k_{\mathrm{nr}}$ causes a reduction of triplet quantum yield (see Eq. (6) and (10)). From Eq. (13) one expects, the ${ }^{1} \mathrm{O}_{2}$ concentration to be proportional to the fluorescence quantum yield. As shown in Fig. 8 this theoretical prediction is fulfilled.

Fig. 9 shows the oxygen phosphorescence intensity as function of the ${ }^{3} \mathrm{O}_{2}$ concentration $\left[{ }^{3} \mathrm{O}_{2}\right]$. The reduction of the ${ }^{3} \mathrm{O}_{2}$ concentration leads to a decreased phosphorescence intensity. For both sensitizers, the measured oxygen dependency can be described by Eq. (5) and (11). As can be seen from Fig. 9 in case of rhodamine $6 \mathrm{G}$ the data measured by the laser-scanning microscope (see Fig. 6(a, c) and Table 2) lead to an excellent agreement with the measured oxygen phosphorescence intensity (only the absolute scaling is fitted). This is a further strong indication that the measured oxygen phosphorescence is indeed sensitized by the rhodamine. By using rose bengal as sensitizer the measured oxygen phosphorescence intensity as function of the ${ }^{3} \mathrm{O}_{2}$ concentration can also be described by Eq. (5). In this case no significant oxygen dependency of the triplet quantum yield is assumed.

In Table 3 the investigated photosensitizers are compared. Rhodamine 630 is known as a dye which possesses a rate constant for intersystem crossing lower than that of rhodamine 6G [65]. As shown in Table 3 this is applicable in acetonitrile as well. The low triplet quantum yield of rhodamine 630 leads to the expected small ${ }^{1} \mathrm{O}_{2}$ concentration.

From the experimental dimensioning typical for the situation described in context with Fig. $7(P=65 \mathrm{~mW}$, $\lambda=514.5 \mathrm{~nm}, V=0.06 \mathrm{~mm}^{3}$ ) follows with Eq. (4) $P_{\mathrm{A}}=$ $4.7 \mathrm{~mol} /(\mathrm{s} \mathrm{s})$. With the assumption $k_{1} \gg k_{3}$ the ${ }^{1} \mathrm{O}_{2}$ concentration in the sensing volume is calculated by Eq. (5) and given in Table 3 .

For rose bengal the measured value for $I_{\Delta} / I_{\Delta}($ rh6G) is approximately three times lower than expected from the triplet yield ratio $\Phi_{\mathrm{ST}} / \Phi_{\mathrm{ST}}(\mathrm{rh} 6 \mathrm{G})$. This is a hint for quenching of ${ }^{1} \mathrm{O}_{2}$ or its precursors by rose bengal in one or more of its electronic states. To ascertain if the ground state or a transient state of rose bengal is operative, methylene blue is used to sensitize singlet molecular oxygen. Methylene blue is excitable outside the absorption band of rose bengal by the $647.1 \mathrm{~nm}$ line of a $\mathrm{Kr}$-ion laser (see Fig. 4). Analysing the oxygen phosphorescence photosensitized by methylene blue as a function of the rose bengal concentration allows to extract the influence of rose bengal ground state selectively. Indeed an efficient reduction of the detected luminescence with increasing rose bengal concentration is observed (not shown). In order to determine the origin of this effect, the triplet lifetime of both methylene blue and rose bengal is measured in dependence on rose bengal concentration. The obtained triplet lifetimes show no influence sufficient to explain the efficient phosphorescence reduction. This deduces a direct quenching of ${ }^{1} \mathrm{O}_{2}$ by rose bengal in its ground state. A strong influence of transient rose bengal molecules on each other or on ${ }^{1} \mathrm{O}_{2}$ can be excluded because of the proportionality between exciting power and phosphorescence intensity. In the literature [66] the mechanism of the quenching effect of ground state rose bengal on ${ }^{1} \mathrm{O}_{2}$ is discussed.

\section{Conclusion}

By measuring its IR phosphorescence the formation of ${ }^{1} \mathrm{O}_{2}$ photosensitized by rhodamine dyes is directly proved. The dye rhodamine 630 possesses a quantum yield for triplet state population which is two times lower than that of rhodamine $6 \mathrm{G}$. The comparison of the formed ${ }^{1} \mathrm{O}_{2}$ concentration photosensitized by these dyes leads to the expected ratio. By using rose bengal as photosensitizer from its high triplet quantum yield a ${ }^{1} \mathrm{O}_{2}$ concentration 40 times higher than that of rhodamine $6 \mathrm{G}$ is expected. Whereas the measured ratio is considerably smaller. As explanation for this difference a direct quenching of ${ }^{1} \mathrm{O}_{2}$ by rose bengal in its ground state is discussed.

It is found for rhodamine $6 \mathrm{G}$ as well as for rose bengal that in air-saturated acetonitrile nearly the half of the excited dye triplets are quenched by molecular oxygen. The ${ }^{1} \mathrm{O}_{2}$ concentration can be significantly reduced by decreasing the ${ }^{3} \mathrm{O}_{2}$ concentration below its air saturated level.

By addition of nitrobenzene and COT the formation of ${ }^{1} \mathrm{O}_{2}$ can be effectively prevented by quenching of the $\mathrm{S}_{1}$ and $\mathrm{T}$ state of the photosensitizer.

\section{Acknowledgements}

We are grateful to Prof. R. Schmidt, University of Frankfurt, for useful discussion during the conception of this project. We thank Prof. Dr. K. H. Drexhage, University of Siegen, for a purified sample of rhodamine 630. Further, we thank S. Nord, University of Heidelberg, for the carefully measurement of the $S_{1}$ lifetimes. We gratefully acknowledge 
financial support by the Deutsche Forschungsgemeinschaft and Fonds der Chemischen Industrie.

\section{References}

[1] R. Rigler, J. Widengren, Ü. Mets, in: Wolfbeis (Ed.), Fluorescence Spectroscopy, Springer, 1992, p. 13.

[2] R.A. Keller, W.P. Ambrose, P.M. Goodwin, J.H. Jett, J.C. Martin, M. Wu, Appl. Spectroscopy 50(7) (1996) 12A.

[3] D.L. Taylor, A.S. Waggoner, R.F. Murphy, F. Lanni, R.R. Birge (Eds.), Applications of Fluorescence in the Biomedical Sciences, Alan R. Liss Inc., New York, 1986.

[4] K.H. Drexhage, in: F. P. Schäfer (Ed.), Dye Lasers, Springer, Berlin-Heidelberg.

[5] O.G. Peterson, in: C.L. Tang (Ed.), Methods of Experimental Physics, Academic Press, New York, 1979.

[6] F.J. Duarte, L.W. Hillmann (Eds.), Dye Laser Principles, Academic Press, New York, 1990.

[7] M.D. Archer, M.I.C. Ferreira, in: J.S. Connolly (Ed.), Photochemical Conversion and Storage of Solar Energy, Academic Press, New York, 1982, p. 201.

[8] J. Chodosh, R.D. Dix, R.C. Howell, W.G. Stroop, S.C.G. Tseng, Invest. Ophthal. Vis. Sci. 35 (1994) 1046.

[9] P. Morlière, R. Santus, M. Bazin, E. Kohen, V. Carillet, F. Bon, J. Rainasse, L. Dubertret, Photochem. Photobiol. 52 (1990) 703.

[10] R.C. Richmond, O'Hara, Photochem. Photobiol. 57 (1993) 291.

[11] F.C. Strome Jr., S.A. Tuccio, IEEE J. Quant. Electr. QE-9 (1973) 230.

[12] O.G. Peterson, in: C.L. Tang (Ed.), Methods of Experimental Physics, Academic Press, New York, 1979, p. 251.

[13] C. Jensen, in: F.J. Duarte (Ed.), High-Power Dye Lasers, Springer, New York, 1991 p. 45.

[14] P.N. Everett, in: F.J. Duarte (Ed.), High-Power Dye Lasers, Springer, New York, 1991, p. 183

[15] L. Hollberg, in: F.J. Duarte, L.W. Hillmann (Eds.), Dye Laser Principles, Academic Press, Boston, 1990, p. 185.

[16] E. Thiel, Eigenschaften angeregter Rhodamin-Farbstoffe und deren Wirkung im Farbstofflaser, Shaker, Aachen, 1996, p. 99.

[17] E. Thiel, Eigenschaften angeregter Rhodamin-Farbstoffe und deren Wirkung im Farbstofflaser, Shaker, Aachen, 1996, p. 23.

[18] R. Menzel, Ph.D Thesis, University of Siegen, 1998.

[19] G. Jones II, in: F.J. Duarte, L.W. Hillmann (Eds.), Dye Laser Principles, Academic Press, Boston, 1990, p. 302.

[20] H.G.O. Becker, Einführung in die Photochemie, Deutscher Verlag der Wissenschaften, Berlin, 1991, p. 381.

[21] N.J. Turro, Modern Molecular Photochemistry, Benjamin, Menlo Park, CA, 1978, p. 579.

[22] H.H. Wasserman, R.W. Murray, Singlet Oxygen, in: H.H. Wasserman (Ed.), Organic Chemistry, vol. 40, Academic Press, New York, 1979.

[23] A.P. Schaap (Ed.), Singlet Molecular Oxygen, Benchmark Papers in Organic Chemistry / 5, Dowden, Hutchinson and Ross, Stroudsburg, 1976.

[24] B. Ranby, J.F. Rabek (Eds.), Singlet Oxygen, Wiley, Chichester, 1978.

[25] A.A. Karasnovsky Jr., Photochem. Photobiol. 29 (1987) 29.

[26] R.W. Redmond, S.E. Braslavsky, Chem. Phys. Lett. 148 (1988) 523.

[27] E. Oliveros, P. Suardi-Murasecco, T. Aminian-Saghafi, A.M. Braun, H.-J. Hansen, Helv. Chim. Acta 74 (1991) 79.

[28] A.U. Kahn, M. Kasha, Proc. Natl. Acad. Sci. USA 91 (1994) 12356.

[29] D.R. Kearns, Chem. Rev. 71 (1971) 395.

[30] J.R. Hurst, J.D. McDonald, G.B. Schuster, J. Am. Chem. Soc. 104 (1982) 2065.
[31] R. Schmidt, J. Phys. Chem. 100 (1996) 8049.

[32] A.N. Macpherson, T.G. Truscott, P.H. Turner, J. Chem. Soc. Faraday Trans. 90 (1994) 1065.

[33] M. Mir, L.M.G. Jansen, F. Wilkinson, J.L. Bourdelande, J. Marquet, J. Photochem. Photobiol. A 113 (1998) 113.

[34] J. Georges, Spectrochim. Acta Rev. 15 (1993) 39.

[35] R. Brennetot, J. Georges, Chem. Phys. Lett. 289 (1998) 19.

[36] E. Gandin, Y. Lion, A. Van de Vorst, J. Photochem. Photobiol. 37 (1983) 271.

[37] H. Rosenand, S.J. Klebanoff, J. Biol. Chem. 252 (1977) 4803.

[38] B. Stevens, B.E. Algar, J. Phys. Chem. 72 (1968) 3794.

[39] B. Stevens, B.E. Algar, Chem. Phys. Lett. 1 (1967) 58.

[40] R.A. Kenley, N.A. Garcia, Dyes Pigments 38 (1998) 195.

[41] G.P. Gurinovich, O.M. Petsol'd, I.M. Byteva, Biofizika 19 (1974) 249. (translated in English in Biophysics, same volume and pages).

[42] M.I. Gutiérrez, N.A. Garcia, Dyes Pigments 38 (1998) 195.

[43] R. Menzel, E. Thiel, Chem. Phys. Lett. 291 (1998) 237.

[44] P. Pal, H.L. Zeng, G. Durocher, D. Girard, T.C. Li, K. Gupta, R. Giasson, L. Blanchard, L. Gaboury, A. Balassy, C. Turmel, A. Laperiére, L. Villeneuve, Photochem. Photobiol. 63 (1996) 161.

[45] C.R. Shea, N. Chen, J. Wimberly, T. Hasan, Cancer Res. 49 (1989) 3961.

[46] P. Morliére, R. Santus, M. Bazin, E. Kohen, V. Carillet, F. Bon, J. Rainasse, L. Dubertret, Photochem. Photobiol. 52 (1990) 703.

[47] P. Meallier, M. Moullet, S. Guittonneau, F. Chabaud, P. Chevrou, C. Niemann, Dyes Pigments 2 (1998) 161.

[48] P. Qu, J. Zhao, T. Shen, H. Hidaka, J. Mol. Catal. A: Chem. 129 (1998) 257.

[49] F.J. Duarte, L.W. Hillmann (Eds.), Dye Laser Principles, Academic Press, New York, 1990, p. 302.

[50] D.C. Neckers, O.M. Valdes-Aguilera, in: D. Volman, G.S. Hammond, D.C. Neckers (Eds.), Advances in Photochemistry, Vol. 18, Wiley, 1993, p. 315.

[51] P. Meallier, A. Desmartin, F. Chabaud, P. Chevrou, C. Nieman, Bull. Soc. Chim. Fr 131 (1994) 949.

[52] M.D. Rahn, T.A. King, A.A. Gorman, I. Hamblett, Appl. Opt. 36 (1997) 5862.

[53] M.W. Ferguson, P.C. Beaumont, S.E. Jones, S. Navaratnam, B.J. Parsons, Phys. Chem. Chem. Phys. 1 (1999) 261.

[54] E. Thiel, K.H. Drexhage, Chem. Phys. Lett. 199 (1992) 329.

[55] S.L. Murov, I. Carmichael, G. L. Hug, Handbook of Photochemistry, Marcel Dekker, New York, 1993, p. 289.

[56] Ma. Heupel, E. Thiel, J. Fluoresc. 7 (1997) 371.

[57] C.R. Lambert, I.E. Kochevar, Photochem. Photobiol. 66 (1997) 15.

[58] R. Menzel, R. Bornemann, E. Thiel, J. Chem. Soc. Faraday Trans., in preparation.

[59] E. Thiel, Eigenschaften angeregter Rhodamin-Farbstoffe und deren Wirkung im Farbstofflaser, Shaker, Aachen, 1996, p. 64.

[60] M. Klessinger, J. Michl, Lichtabsorption und Photochemie organischer moleküle, VCH, Weinheim, 1989, p. 217.

[61] D.C. Neckers, J. Chem. Ed. 64 (1987) 649.

[62] J. Paczkowski, J.J.M. Lamberts, B. Paczkowska, D.C. Neckers, J. Free Radicals Biol. Med. 1 (1985) 341.

[63] G.R. Fleming, A.W.E. Knight, J.M. Morris, R.J.S. Morrison, G.W. Robinson, J. Am. Chem. Soc. 99 (1977) 4306.

[64] V.V. Shereshhovets, N.N. Kabalnova, V.D. Komissarov, V.K. Mavrodiev, B.M. Lerman, T.A. Belogaeva, G.A. Tolstikov, React. Kinet. Catal. Lett. 41 (1990) 251.

[65] E. Thiel, Eigenschaften angeregter Rhodamin-Farbstoffe und deren Wirkung im Farbstofflaser, Shaker, Aachen, 1996, p. 85.

[66] C. Tanielian, L. Golder, C. Wolff, J. Photochem. 25 (1984) 117.

[67] M.A.J. Rodgers, Photochem. Photobiol. 37 (1983) 99. 